\title{
Ofatumumab Regimen
}

National Cancer Institute

\section{Source}

National Cancer Institute. Ofatumumab Regimen. NCI Thesaurus. Code C160096.

An immunotherapy regimen consisting of ofatumumab that may be used in the treatment of chronic lymphocytic leukemia (CLL)/small lymphocytic lymphoma (SLL), and Waldenstrom's macroglobulinemia (WM)/lymphoplasmacytic lymphoma (LPL). 